\title{
IRF5 gene polymorphisms in melanoma
}

\author{
Lorenzo Uccellini ${ }^{1}{ }^{2 *}$, Valeria De Giorgi ${ }^{1}$, Yingdong Zhao ${ }^{3}$, Barbara Tumaini ${ }^{4}$, Narnygerel Erdenebileg ${ }^{1}$, \\ Mark E Dudley ${ }^{6}$, Sara Tomei ${ }^{1}$, Davide Bedognetti ${ }^{1,5}$, Maria Libera Ascierto ${ }^{1,5}$, Qiuzhen Liu', Richard Simon ${ }^{3}$, \\ Leah Kottyan ${ }^{6}$, Kenneth M Kaufman ${ }^{6,7}$, John B Harley ${ }^{6,7}$, Ena Wang ${ }^{1}$, Steven A Rosenberg ${ }^{1}$ and \\ Francesco M Marincola ${ }^{8^{*}}$
}

\begin{abstract}
Background: Interferon regulatory factor (IRF)-5 is a transcription factor involved in type I interferon signaling whose germ line variants have been associated with autoimmune pathogenesis. Since relationships have been observed between development of autoimmunity and responsiveness of melanoma to several types of immunotherapy, we tested whether polymorphisms of IRF5 are associated with responsiveness of melanoma to adoptive therapy with tumor infiltrating lymphocytes (TILs).
\end{abstract}

Methods: 140 TILs were genotyped for four single nucleotide polymorphisms (rs10954213, rs11770589, rs6953165, rs2004640) and one insertion-deletion in the IRF5 gene by sequencing. Gene-expression profile of the TILs, 112 parental melanoma metastases (MM) and 9 cell lines derived from some metastases were assessed by Affymetrix Human Gene ST 1.0 array.

Results: Lack of A allele in rs10954213 (G>A) was associated with non-response ( $p<0.005)$. Other polymorphisms in strong linkage disequilibrium with rs10954213 demonstrated similar trends. Genes differentially expressed in vitro between cell lines carrying or not the A allele could be applied to the transcriptional profile of 112 melanoma metastases to predict their responsiveness to therapy, suggesting that IRF5 genotype may influence immune responsiveness by affecting the intrinsic biology of melanoma.

Conclusions: This study is the first to analyze associations between melanoma immune responsiveness and IRF5 polymorphism. The results support a common genetic basis which may underline the development of autoimmunity and melanoma immune responsiveness.

\section{Introduction}

The development of autoimmunity in patient with malignant melanoma has been linked to tumor regression following immunotherapy with interleukin (IL)-2, interferon (IFN) $\alpha$ or anti-Cytotoxic T-Lymphocyte Antigen (CTLA)-4. Examples include hypothyroidism [1,2], vitiligo [3], anti-phospholipids syndrome [4] and autoimmune retinopathy [5]. In particular, the fact that effective immune responses against melanoma are associated with the development of vitiligo [3], which results from autoimmune destruction of normal melanocytes, reinforces

\footnotetext{
* Correspondence: uccellinilorenzo@gmail.com; fmarincola@mail.cc.nih.gov ${ }^{1}$ Infectious Disease and Immunogenetics Section (IDIS), Department of Transfusion Medicine, Clinical Center and trans-NIH Center for Human Immunology, National Institutes of Health, Bethesda, MD 20892, USA ${ }^{8}$ Surgery Branch, National Cancer Institute, National Institutes of Health, Bethesda, MD, USA

Full list of author information is available at the end of the article
}

the pathogenic commonality between autoimmunity and cancer rejection.

Several studies support the hypothesis that distinct immune-mediated tissue-specific destruction (TSD) processes such as autoimmunity, cancer rejection, allograft rejection, graft versus host disease, or acute infection resulting in clearance of pathogens share convergent final mechanisms [6-9]; we have previously defined this phenomenon as the immunological constant of rejection (ICR) [6]. The ICR includes the coordinate expression of genes controlling antigen presentation, interferonstimulated genes (ISGs) and immune effectors functions (IEFs). The suggestion that the phenomena of immunemediated cancer rejection and autoimmunity represent different faces of TSD, leads to the conjecture that factors responsible for autoimmunity might also be relevant to the immunotherapy of cancer.

\section{Biomed Central}


Systemic Lupus Erythematosus (SLE) is the prototype for systemic autoimmune disease. An important step to understand the pathogenesis of SLE was the appreciation for the dominant role played by type I IFNs [10,11]. Variants of genes within the IFN pathway like interferon regulatory factor (IRF)-5 have been associated with SLE by multiple studies [12,13] and have been repeatedly implicated in susceptibility to several other autoimmune diseases including rheumatoid arthritis [14], multiple sclerosis [15,16], inflammatory bowel disease [17] and Sjogren's syndrome [12,18]. IRF5 is involved in host defense against pathogens by inducing transcription of IFN $\alpha$ [19] and the expression of genes involved in apoptosis [20,21]. Three functional variants of IRF5 that are associated with SLE risk have been touted to define the risk to develop SLE: including a splice site, a 30 base pair in-frame insertion/deletion, and an alternative polyadenylation site in the 3'UTR region [22]; however, no fine mapping study has been reported to establish whether these, over the many other variants, including an interesting promoter variant [23] are preferred as explanations for SLE risk.

The prominent role played by IRF5 variants in determining the risk to develop autoimmunity suggests a possible role for IRF5 as modulator of immune responsiveness of melanoma. However, to our knowledge, IRF5 polymorphisms have never been studied in the context of melanoma. Therefore, we investigated whether polymorphisms in IRF5 associated to SLE are also associated with melanoma responsiveness to immunotherapy. Concordant to results obtained in SLE, the lack of the A allele in rs10954213 (G > A) that is protective against the development of SLE was associated to non-responsiveness to treatment among 140 patients with metastatic melanoma who received the adoptive transfer of tumor infiltrating lymphocytes (TILs). Remarkably, transcriptional changes observed between melanoma cell lines carrying or not the A allele could be used to predict responsiveness of 112 melanoma metastases (MM), suggesting that the IRF5dependent immune responsiveness is at least partly related to the intrinsic biology of melanoma.

\section{Materials and methods \\ Patient samples}

TILs were expanded in vitro from 140 excised melanoma metastases for reinfusion into patients following lymphodepletion of the host. An aliquot from each TIL preparation were cryo preserved on the day of infusion. Samples were collected during 5 consecutive trials at the Surgery Branch, National Cancer Institute (NCI) [24,25]. Before TIL administration, patients received nonmyeloablative lymphodepletion consisting of cyclophosphamide at $60 \mathrm{mg} / \mathrm{Kg} / \mathrm{d}$ for 2 days and fludarabine at $25 \mathrm{mg} / \mathrm{m} 2 / \mathrm{d}$ for 5 days [24]. Two Gy or 12 Gy total body irradiation
(TBI) was administered in conjunction with chemotherapy in T200 and T1200 trials, respectively. Within 1 day of completion of lymphodepletion, TILs were infused and high-dose IL-2 therapy was started (720,000 IU/Kg intravenously every 8 hours to tolerance). Two days after TIL infusion, patients treated with TBI also received autologous purified CD34+ hematopoietic stem cells from a granulocyte colony-stimulating factor \pm plerixafor.

Different protocols were employed to generate TILs [24-26]. A 'classic' method employing an extended duration of multiple microcultures and an individualized assay to identify tumor recognition was used for TNMA, T200, T1200 trials [24,26]. A simplified method using short-term cultured 'young' TILs unscreened for tumorreactivity were used in TYT and TCD8 trials [25]. TILs were depleted from CD4+ cells in TCD8 trial [25].

Inclusion criteria for the trials were: age $\geq 18$, measurable disease, good clinical performance and a life expectancy above 3 months. All patients signed an informed consent approved by the NCI Institutional Review Board. Data for this analysis are updated as of January $11^{\text {th }}, 2012$. Response (complete response CR, partial response PR or no response NR) was assessed using the Response Evaluation Criteria in Solid Tumors (RECIST) guidelines starting approximately 4 weeks after TIL administration and at regular intervals thereafter. A CR or PR was considered an overall response (R).

TIL samples from 142 melanoma patients under adoptive transfer therapy were available: RNA and DNA were isolated from the same 140 TIL with 2 additional TIL for RNA only. 112 pre-treatment snap-frozen tumor biopsies used for the TIL generation were used for RNA extraction. RNA and DNA were also isolated from 15 melanoma cell lines derived from the 112 melanoma lesions.

\section{Genotyping}

Four single nucleotide polymorphisms (SNPs) rs10954213, rs11770589, rs6953165, rs2004640 and one insertiondeletion in exon 6 of IRF5 were genotyped by sequencing 140 TILs. PCR was carried out in a reaction mixture containing $40 \mathrm{ng}$ of DNA, $10 \mu \mathrm{l}$ of HotStar Taq Master Mix (Qiagen, Germantown, MD) and 100 pmol of each of the following primers: for rs10954213/ rs11770589, forward 5-CCCTGATTTCCCTGGTTTG-3 and reverse 5'-AGCCAGCCAGGTGAGTGTT-3'; for rs6953165/rs2004640 forward 5'-CACCGCAGACAGG TGGG-3', reverse 5'-GGGAGGCGCTTTGGAAGT-3'; for insertion-deletion in exon 6 forward 5'-CCCCACATGAC ACCCTATTC-3' and reverse 5'-GGCTGGGGTCTGG AGCAG-3'. The reaction mixture was denatured at $95^{\circ} \mathrm{C}$ for 15 minutes and cycled 35 times at $94^{\circ} \mathrm{C}$ for 45 seconds, $\mathrm{T}_{\mathrm{a}}$ for 45 seconds $\left(\mathrm{T}_{\mathrm{a}}=55^{\circ} \mathrm{C}\right.$ for rs10954213 / rs11770589; $\mathrm{T}_{\mathrm{a}}=56^{\circ} \mathrm{C}$ for $\mathrm{rs} 6953165 / \mathrm{rs} 2004640 ; \mathrm{T}_{\mathrm{a}}=58^{\circ} \mathrm{C}$ for 
insertion-deletion), $72^{\circ} \mathrm{C}$ for 60 seconds, with final extension at $72^{\circ} \mathrm{C}$ for 10 minutes. PCR product was treated with Exosap-IT (USB Corporation, Cleveland, $\mathrm{OH}$ ) to removed excess primers. $3.5 \mu \mathrm{l}$ out of 20 of purified DNA product was combined with $2.0 \mu \mathrm{l}$ of Big Dye terminator (ABI Prism Big Dye Terminator cycle sequencing ready reaction kit v3.1, Applied Biosystems, Foster City, CA) and $100 \mathrm{pmol}$ of forward primer. The sequencing reaction was carried out for 30 cycles of denaturation $\left(96^{\circ} \mathrm{C} / 1 \mathrm{~m}\right)$, annealing $\left(50^{\circ} \mathrm{C} / 30 \mathrm{~s}\right)$ and extension $\left(60^{\circ} \mathrm{C} / 4 \mathrm{~m}\right)$. Excess dye terminators were removed using DyeEx 96 Kit columns as per Manufacturer's instructions (Qiagen Inc. Germantown, MD). Electrophoresis was performed on ABI Prism $3730 \mathrm{XL}$ instrument (Applied Biosystems, Foster City, CA).

\section{Statistical analysis}

In this explorative analysis, no stratification of patients was done according to distinct TIL protocols with the assumption that the genetic background of the patient would have an independent effect on responsiveness to the conceptually similar therapeutic protocols studied here. Association analyses were conducted by chi-square test using $2 \times 2$ and $2 \times 3$ contingency tables. When 1 or more variables in the contingency table were $\leq 5$, Fisher's exact test was used. Two side probability values $\left(\mathrm{p}_{2}\right.$-value $)<0.05$ were considered to be statistically significant. In gene expression data analysis, the variance of the log-intensity for each gene was compared to the median of all the variances. Those genes not significantly more variable than the median gene were filtered out $(\mathrm{p}>0.01)$. For class comparison in cell lines with replicates, a linear mixed-effects model was used for each gene (implemented in BRB-ArrayTools). Cell line was specified as random effect and IFN $\alpha$ and genotype were specified as fixed factors. Genes that were differentially expressed between genotype "A" and "G" groups were identified after accounting for the differences in expression in IFN $\alpha+$ and IFN $\alpha$ - groups. A list of genes whose expression changes due to IFN $\alpha$ were also identified by adjusting for any imbalances in the "A" to "G" ratio in the IFN $\alpha+$ and IFN $\alpha$ - groups. To confirm the segregation of two distinct groups in class comparison analysis data, a K-means clustering algorithm was performed that chooses a pre-specified number of cluster centers to minimize the within class sum of squares from those centers [27].

Calculation of linkage disequilibrium (LD) parameters ( $\mathrm{r}^{2}$ and $\left.\mathrm{D}^{\prime}\right)$ based on genotype data from 140 patients was performed using LDPlotter tool from https://pharmgat.org/Tools.

\section{Gene expression profiling}

We generated 3 independent gene expression data sets from 140 TIL samples, 112 melanoma metastases and 9 cell lines out of 15 that were homozygous for a given IRF5 haplotype and had been expanded from some of the metastases. Total RNA was extracted using miRNeasy minikit (Qiagen, Germantown, MD). The cell lines were treated with $1000 \mathrm{U} / \mathrm{mL}$ IFN $\alpha 2 \mathrm{~b}$ and RNA was isolated after 9 hours. RNA quality and quantity was estimated using Nanodrop (Thermo Scientific, Wilmington, DE) and Agilent 2100 Bioanalyzer (Agilent Technologies, Palo Alto, CA). RNA was amplified from $300 \mathrm{ng}$ of total RNA (Ambion WT Expression Kit). cDNA was reverse transcribed with biotinilation and hybridized to the GeneChip Human Gene 1.0 ST Arrays (Affymetrix WT Terminal Labeling Kit,) after fragmentation. The arrays were washed and stained on a GeneChip Fluidics Station 450 (Affymetrix, Santa Clara, CA); scanning was carried out with the GeneChip Scanner 3000 and image analysis with the Affymetrix GeneChip Command Console Scan Control. Expression data were normalized using the RMA algorithm, http://www.partek.com (Partek Inc., St. Louis, MO and log-transformed (base 2) for parametric analysis and cluster analysis was based on Partek software. Functional interpretations were based on Ingenuity Pathways Analysis software (http://www.ingenuity.com (Ingenuity Systems, Inc., Redwood City, CA).

\section{Results}

\section{Genotyping results}

Genotyping of TILs - Sequencing germline DNA extracted from 140 TILs for IRF5 rs10954213, rs11770589 and rs6953165, rs2004640 and one insertion-deletion in exon 6 demonstrated that genotype frequency distribution was significantly different between responders and nonresponders (Table 1). All IRF5 variants but rs2004640 were associated with immune responsiveness. The lack of the A allele in rs10954213 was predominant in non-responders (rs10954213: AA + AG: 63R vs. 50NR, GG: 7R vs. 20NR, $\mathrm{P}=0.005$ ), (Table 2). All investigated polymorphisms but rs2004640 are in LD with each other in both responders and non-responders $\left(r^{2}=1, D^{\prime}=1\right.$, Figure 1$)$. Because of the strong linkage disequilibrium among the different variants, we selected one (rs10954213) that provided the highest predictive value for subsequent class comparison analyses as representative of the IRF5 extended haplotype. Moreover, because the presence of the A allele in this SNP was associated with immune responsiveness independent of homo/hetorozygosity, we split samples into an " $\mathrm{A}$ " allele carrier (AA + AG) and an "A" allele missing (GG) group.

Genotyping of cell lines - all the 15 cell lines were genotyped for rs10954213 (G > A) polymorphism to test the degree in which this trait was conserved within the instable genetic background of cancer cells. All of the cell lines displayed the genetic profile predicted by the germline analysis with the exception of one (3025 Mel), which demonstrated loss of heterozygosis ( $\mathrm{LOH}$, loss of 
Table 1 IRF5 genotype frequencies

\begin{tabular}{llllll}
\hline & Genotype & R & NR & \#total & P \\
\hline rs10954213 & AA & $33(63.5)$ & $19(36.5)$ & $52(37.1)$ & 0.007 \\
& AG & $30(49.2)$ & $31(50.8)$ & $61(43.6)$ & \\
& GG & $7(25.9)$ & $20(74.1)$ & $27(19.3)$ & \\
rs1177589 & AA & $18(60)$ & $12(40)$ & $30(21.4)$ & 0.012 \\
& AG & $39(57.4)$ & $29(42.6)$ & $68(48.6)$ & \\
& GG & $13(31)$ & $29(69)$ & $42(30)$ & \\
rs2004640 & GG & $16(43.2)$ & $21(56.8)$ & $37(26.5)$ & 0.6219 \\
& GT & $34(53.2)$ & $30(46.8)$ & $64(45.7)$ & \\
& TT & $20(51.2)$ & $19(48.8)$ & $39(27.8)$ & \\
& CC & $66(60)$ & $57(40)$ & $123(87.9)$ & 0.059 \\
& GG & $4(57.4)$ & $12(42.6)$ & $16(11.4)$ & \\
& GG & $0(31)$ & $1(69)$ & $1(0.7)$ & \\
exon6 & del/del & $18(60)$ & $12(40)$ & $30(21.4)$ & 0.011 \\
& ins/del & $39(57.4)$ & $29(42.6)$ & $68(480.6)$ & \\
& ins/ins & $13(31)$ & $29(69)$ & $42(30)$ & \\
\hline
\end{tabular}

the A allele; AG > G genotype) (Table 3). This loss was significant because it leads to the absence of the dominant " $\mathrm{A}$ " allele determining immune responsiveness. For this reason, although the patient bore a mixed genotype, the hemi-zygotic " $G$ " cell line was considered together with the "G" homozygous cell lines for class comparison. However, the patient and corresponding tumor were considered still heterozygous because there is no clear evidence that the cell line genotype was representative of the cancer cells in vivo, nor it was known whether the transcriptional profile of tumors containing a mixed population of cancer and normal cells would be predominantly affected by one or the other. In addition, it is not known whether the IRF5 genotype of the tumor or some other cell type, such as an immune cell, is where the genotype is relevant to the immune-responsiveness phenotype. Certainly, if there an elevated proportion of patients have metastases showing loss of heterozygosity the "A" allele at IRF5, then this would imply that the IRF5 genotype of the tumor itself is important. In any case, the frequency of $\mathrm{LOH}$ was $<10 \%$. Thus, we estimated, for the purpose of further analysis, that the genotype of cancer cells in tumor tissues was conserved in approximately $90 \%$ of cases and conducted further class

Table 2 IRF5 rs10954213-TILs association

\begin{tabular}{lllll}
\hline Genotype & R & NR & Total & P \\
\hline AA + AG & $63(55.8)$ & $50(44.2)$ & $113(81.0)$ & 0.005 \\
GG & $7(25.9)$ & $20(74.1)$ & $27(19.0)$ & \\
& & & $140(100)$ & \\
\hline
\end{tabular}

comparisons classifying metastases according to the genetic background of the corresponding patient.

\section{Gene expression profiling Cell lines}

Nine of the 15 cell lines generated from the melanoma metastases were analyzed for functional differences according to their IRF5 genotype; the genetic profile of these cell lines and its relationship with the parental tumors has been extensively described elsewhere [28]. To test whether differences between IRF5 genotype bear any effects on the intrinsic biology of cancer cells without the influence of the microenvironment, we cultured the 9 cell lines with or without IFN $\alpha$ and compared transcriptional patterns according to their IRF5 rs10954213 genotype. Seven cell lines out of the 15 bore the more frequent "AA" genotype but one of them stopped growing in culture, reducing to 6 the number of cell line analyzed; whereas three (including the "G" hemizygous cell line) bore only the GG allele. Principal Component Analysis (PCA) (Figure 2) demonstrated that identical cell lines distributed closely in three-dimensional spaces independently of the treatment with IFN $\alpha$ with the three G only carrying cell lines clustering close together. IFN $\alpha$ predicatively affected the expression of 1,411 genes $(\mathrm{p}<0.01)$, mostly related to IFN signaling (see Additional file 1: Table S1). We identified 106 differentially expressed genes between " $A$ " and "G" groups using a linear mixed-effects model $(\mathrm{p}<0.01)$. Gene enrichment analysis suggested that the predominantly affected pathways were related to antigen presentation, immune response, allograft rejection, autoimmunity and metabolism.

\section{Re-clustering of melanoma metastases based on transcripts differentiating melanoma cell lines with distinct IRF5 genotype}

The 106 gene signature differentiating melanoma cell lines in vitro was applied to produce a heat map of melanoma metastases based on $\mathrm{K}$ mean clustering method (Figure 3). This experiment identified a subset of metastases significantly enriched in non-responders. Interestingly, while this signature appeared to strongly predict lack of immune responsiveness, it was less predictive of the IRF5 genotype of the patient, suggesting that the relationship between the two parameters is complex and multifactorial. K-means clustering algorithm, performed on the class comparison of metastases based on transcripts differentiating melanoma cell lines with distinct IRF5 genotype, segregated two groups of patients. The group 2 includes 46 responders and 32 non-responders, while the group 1 includes 12 responders and 22 nonresponders, with in this case inclusion of a large majority of GG genotypes (Fisher test: $\mathrm{p}_{2}$-value $=0.025$ ). 


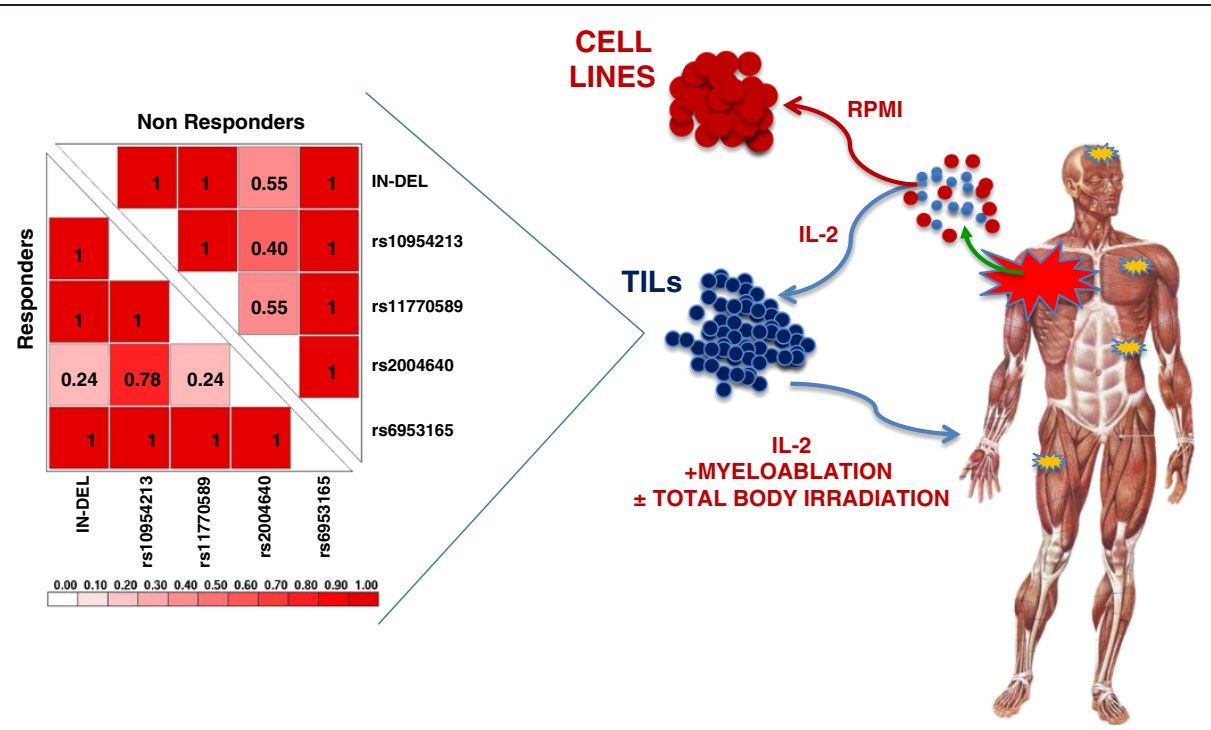

Figure 1 (Left) Pairwise linkage disequilibrium between IRF5 polymorphisms in tumor infiltrating lymphocytes (TILs). $D^{\prime}$ and $r^{2}$ were calculated using LDPlotter tool. D' values for linkage disequilibrium among the major alleles of each of IRF5 are shown. IN-DEL=insertion/ deletion. (Right) Samples studied: 140 TILs, 112 parental melanoma metastases and 9 cell lines derived from some metastases.

\section{Discussion}

Several studies support a link between autoimmunity and cancer immune responsiveness, suggesting that the two phenomena share a common determinism. Thus, we hypothesized that factors relevant to autoimmunity might also be relevant to cancer immunotherapy. The IRF5 gene has been associated with SLE in multiple ethnic groups and repeatedly implicated in susceptibility to

Table 3 Fifteen melanoma cell lines genotype compared with the germline

\begin{tabular}{lccc}
\hline \multicolumn{2}{c}{ Cell lines ID } & \multicolumn{2}{c}{ rs10954213 (G > A) } \\
\cline { 2 - 4 } & & Melanoma cell lines & Germline \\
\hline TIL_120 & 3104 & AA & AA \\
TIL_064 & 2458 & AA & AA \\
TIL_121 & 3107 & AA & AA \\
TIL_030 & 2155 & AA & AA \\
TIL_077 & 2744 & AA & AA \\
TIL_048 & 2492 & AA & AA \\
TIL_047 & 2448 & AA & AA \\
TIL_032 & 2224 & AG & AG \\
TIL_062 & 2523 & AG & AG \\
TIL_013 & 2035 & AG & AG \\
TIL_040 & 2427 & AG & AG \\
TIL_016 & 2075 & AG & AG \\
TIL_109 & 3025 & YG (LOH) & AG \\
TIL_005 & 1866 & GG & GG \\
TIL_088 & 2805 & GG & GG \\
\hline
\end{tabular}

* $\mathrm{LOH}=$ Loss Of Heterozygosis. many autoimmune diseases, becoming a rationale for the focus of our study. Consistent with the concept that autoimmunity and cancer rejection might represent different facets of the same phenomenon, we observed that polymorphisms protecting against the susceptibility to develop SLE [12,13], such as the IRF5 rs10954213 GG genotype, were significantly more prevalent among patients who did not respond to adoptive TIL therapy.

We analyzed cell lines grown from 9 metastases to test the weight of the IRF5 genotype on the intrinsic biology of cancer cells independent of microenvironment influences. This allowed us to test the ability of the IRF5 genotype to predict immune responsiveness in vivo. We applied the signatures of genes differentiating the 2 cell line genotypes in vitro to the melanoma metastases in vivo and observed a significant segregation of responders from non-responders, leading to the conclusion that immune responsiveness is at least in part dependent upon the genetic background of the host, which affects the biology of cancer cells primarily, and secondarily the immune responsiveness of tumors.

It is interesting to observe that the IRF5 genotype appeared to segregate 2 different cases. When genes differentiating melanoma cell lines in vitro according to genotype were applied for class prediction, a segregation of responding and non responding cases was observed and it was only partially predictive of the IRF5 genotype in vivo. The resulting segregation of cases according to genotype was associated with likelihood of responsiveness. However, there were cases lacking the genetic background predictive of susceptibility to therapy that still did not respond to the treatment. This is a classic 


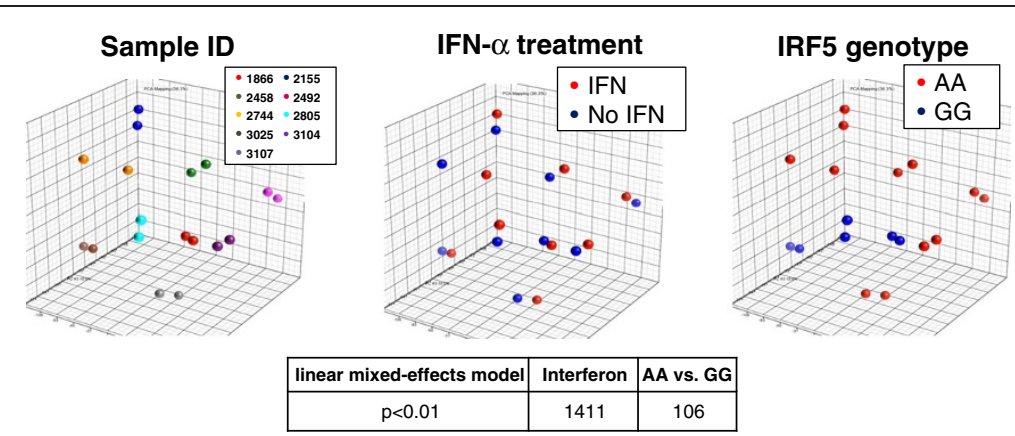

Figure 2 (Top panel) Principal Component Analysis (PCA) based on the gene expression profile of 9 out of 15 melanoma cell lines. The 3D displays of the PCA are color coded by sample ID, IFNa treatment, and IRF5 genotype, respectively. (Bottom panel) Gene expression analysis of cell lines using linear mixed-effects model shows 106 genes were found significant $(p<0.01)$ for testing the genotype effect and 1411 genes were found significant $(p<0.01)$ for testing the interferon effect.

example of the multifactorial road to immune responsiveness [29] underlining that multiple factors may be necessary to allow response to therapy, among which the host genetic background is one. Thus, it is possible that this separate set of genes has distinct yet complementary influences on immune responsiveness.

Fine mapping studies now underway suggest that there are two independent associations with IRF5 defining risk for lupus (L. Kottyan, J. Harley, K.M. Kaufman, unpublished data). The markers identified as being associated with the responses to TILs in this study are more associated with the association located in the promoter of IRF5. In addition, in lupus there are suggestive data that sub-phenotypes also have variable associations with IRF5 alleles [30], suggesting rich variation in the IRF5 control of immune responsiveness.
As a theoretical limitation of this study, we refrained from genotyping the melanoma metastases with the assumption that polymorphisms of the germline were sufficiently representative. Due to the genetic instability of the tumor genome, genotyping the tumor DNA instead of the germline DNA would be ideal for association studies. However, tumor tissue samples are composed of heterogeneous cell types and it is not clear which one mostly contributes to immune responsiveness. Thus, this study was aimed only at the predictive effects of the genetic background of the host. On the other hand, comparison of 15 cell lines with their parental tumors suggested that in the large majority of cases the IRF5 gene was conserved. The frequency of $\mathrm{LOH}$ was $<10 \%$, which is close to other estimates of $\mathrm{LOH}$ prevalence for genes not directly related to oncogenesis such as the

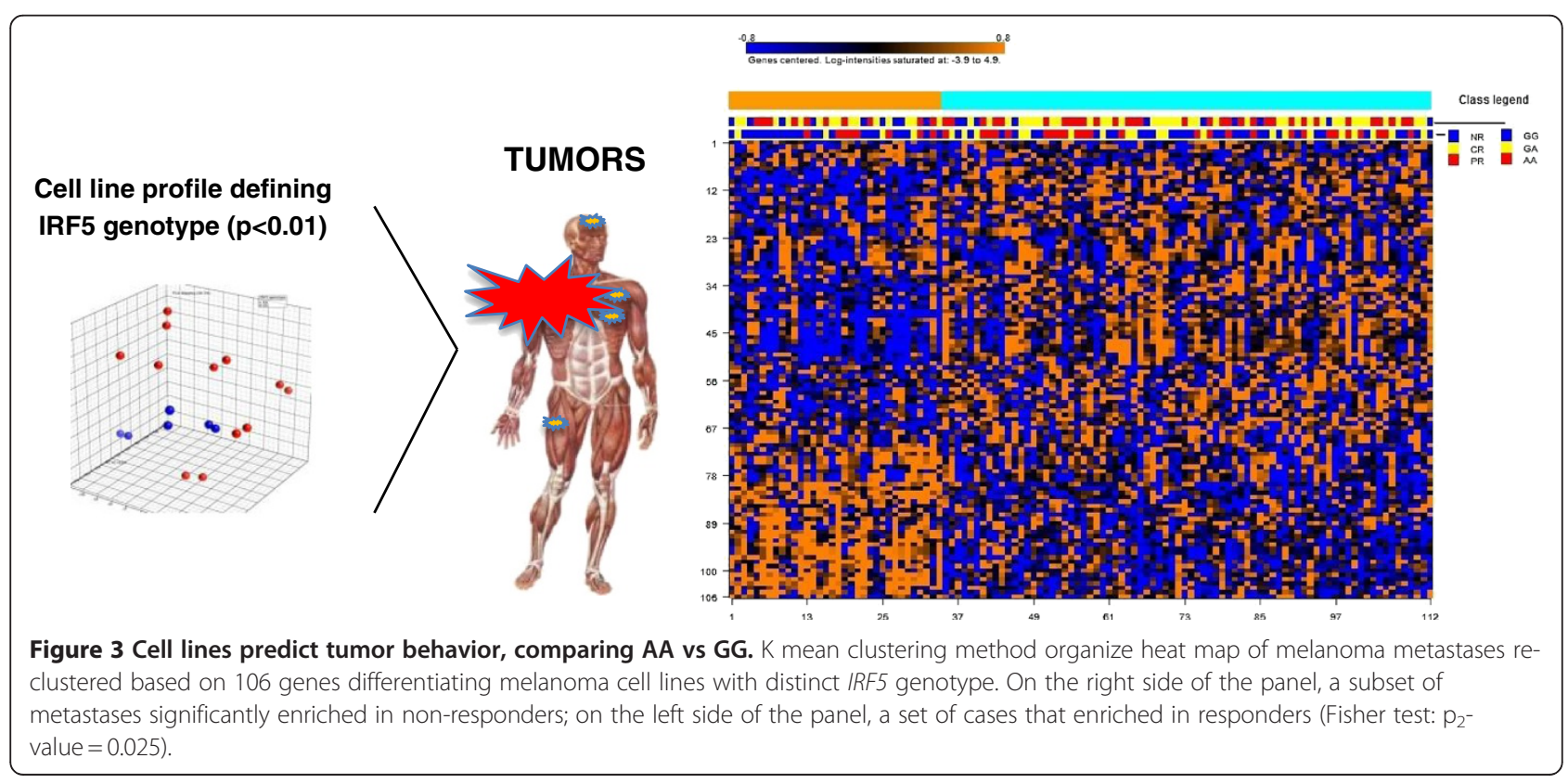


human leukocyte antigen class I genes [31-33]. Thus, we are confident that this analysis approximates the results that could be obtained if the analysis could have been adjusted according to potential somatic changes in the IRF5 gene.

In conclusion, polymorphism of IRF-5 appears to be a predictor of immune responsiveness of melanoma metastases to adoptive therapy with TILs. Comparison of melanoma cell lines classified according to the AA vs. GG rs10954213 (G>A) suggested significant differences in global transcription enriched in genes related to immune regulation. The signatures differentiating the 2 cell line genotypes in vitro are predictive of the responsiveness of melanoma metastases in vivo. Thus, it appears that immune responsiveness is at least in part dependent on the genetic background of the host, which affects the biology of cancer cells primarily and secondarily the immune responsiveness of tumors. This is the first study analyzing the role of IRF5 gene polymorphism in determining immune responsiveness of melanoma. The results provide a link between the determinism of autoimmunity and immune responsiveness and suggest a potential genetic marker that could be evaluated prospectively and eventually considered for future patient stratification.

\section{Additional file}

Additional file 1: Table S1. Table of significant genes for testing 'genotype' effect (106 genes were found significant at level 0.01).

\section{Competing interests}

The authors declare that they have no competing interests.

\section{Authors' contribution}

FMM LU conceived the study, LU performed the experiments. LU YZ VDG FM analyzed the data. LU and FM drafted the manuscript, JHB KMK LK revised data and manuscript. BT NE MED ST DB QL MLA RS WE SAR revised critically the manuscript for important intellectual content and for the language. All the authors read and approved the final manuscript.

\section{Acknowledgments}

DB's fellowship was supported by the Conquer Cancer Foundation of the American Society of Clinical Oncology.

\footnotetext{
Author details

${ }^{1}$ Infectious Disease and Immunogenetics Section (IDIS), Department of Transfusion Medicine, Clinical Center and trans-NIH Center for Human Immunology, National Institutes of Health, Bethesda, MD 20892, USA. ${ }^{2}$ Institutes of Infectious and Tropical Diseases, University of Milan, L Sacco Hospital, Milan, Italy. ${ }^{3}$ Biometric Research Branch, Division of Cancer Treatment and Diagnosis, National Cancer Institute, National Institutes of Health, Bethesda, MD 20892, USA. ${ }^{4}$ Cell Processing Section, Department of Transfusion Medicine, Clinical Center, National Institutes of Health, Bethesda, MD 20892, USA. ${ }^{5}$ Department of Internal Medicine (DiMI), University of Genoa, Genoa 16132, Italy. ${ }^{6}$ Center for Autoimmune Genomics and Etiology (CAGE), Cincinnati Children's Hospital Medical Center, Cincinnati, $\mathrm{OH} 45229$, USA. ${ }^{7}$ U S Department of Veterans Affairs Medical Center, Cincinnati, $\mathrm{OH}$ 45229, USA. ${ }^{8}$ Surgery Branch, National Cancer Institute, National Institutes of Health, Bethesda, MD, USA
}

Received: 30 July 2012 Accepted: 1 August 2012

Published: 21 August 2012

\section{References}

1. Gogas H, loannovich J, Dafni U, Stavropoulou-Giokas C, Frangia K, Tsoutsos D, Panagiotou P, Polyzos A, Papadopoulos O, Stratigos A, et al: Prognostic significance of autoimmunity during treatment of melanoma with interferon. N Engl J Med 2006, 354:709-718.

2. Atkins MB, Mier JW, Parkinson DR, Gould JA, Berkman EM, Kaplan MM Hypothyroidism after treatment with interleukin-2 and lymphokineactivated killer cells. N Engl J Med 1988, 318:1557-1563.

3. Phan GQ, Attia P, Steinberg SM, White DE, Rosenberg SA: Factors associated with response to high-dose interleukin-2 in patients with metastatic melanoma. J Clin Oncol 2001, 19:3477-3482.

4. Naldi L, Locati F, Finazzi G, Barbui T, Cainelli T: Antiphospholipid syndrome associated with immunotherapy for patients with melanoma. Cancer 1995, 75:2784-2785.

5. Chan C, O'Day J: Melanoma-associated retinopathy: does autoimmunity prolong survival? Clin Experiment Ophthalmol 2001, 29:235-238.

6. Wang E, Worschech A, Marincola FM: The immunologic constant of rejection. Trends Immunol 2008, 29:256-262.

7. Wang E: Marincola FM: Immunologic signatures of rejection. New York, NY: Springer; 2010.

8. Ascierto ML, De Giorgi V, Liu Q, Bedognetti D, Murtas D, Chouchane L, Wang E, Marincola FM: An immunologic portrait of cancer. J Transl Med 2011, 9:146.

9. Spivey TL, Uccellini L, Ascierto ML, Zoppoli G, De G V, Delogu LG, Engle AM, Thomas JM, Wang E, Marincola FM, et al: Gene expression profiling in acute allograft rejection: challenging the immunologic constant of rejection hypothesis. J Trans/ Med 2011, 9:174.

10. Blanco P, Palucka AK, Gill M, Pascual V, Banchereau J: Induction of dendritic cell differentiation by IFN-alpha in systemic lupus erythematosus. Science 2001, 294:1540-1543.

11. Pascual V, Farkas L, Banchereau J: Systemic lupus erythematosus: all roads lead to type I interferons. Curr Opin Immunol 2006, 18:676-682.

12. Ronnblom L: The type I interferon system in the etiopathogenesis of autoimmune diseases. Ups J Med Sci 2011, 116:227-237.

13. Graham RR, Kozyrev SV, Baechler EC, Reddy MV, Plenge RM, Bauer JW, Ortmann WA, Koeuth T, Gonzalez Escribano MF, Pons-Estel B, et al: A common haplotype of interferon regulatory factor 5 (IRF5) regulates splicing and expression and is associated with increased risk of systemic lupus erythematosus. Nat Genet 2006, 38:550-555.

14. Dawidowicz K, Allanore Y, Guedj M, Pierlot C, Bombardieri S, Balsa A Westhovens R, Barrera P, Alves $H$, Teixeira VH, et al: The interferon regulatory factor 5 gene confers susceptibility to rheumatoid arthritis and influences its erosive phenotype. Ann Rheum Dis 2011, 70:117-121.

15. Vandenbroeck K, Alloza I, Swaminathan B, Antiguedad A, Otaegui D, Olascoaga J, Barcina MG, de IHV, Fernandez-Arquero M, et al: Validation of IRF5 as multiple sclerosis risk gene: putative role in interferon beta therapy and human herpes virus-6 infection. Genes Immun 2011, 12:40-45.

16. Kristjansdottir G, Sandling JK, Bonetti A, Roos IM, Milani L, Wang C, Gustafsdottir SM, Sigurdsson S, Lundmark A, Tienari PJ, et al: Interferon regulatory factor 5 (IRF5) gene variants are associated with multiple sclerosis in three distinct populations. J Med Genet 2008, 45:362-369.

17. Dideberg V, Kristjansdottir G, Milani L, Libioulle C, Sigurdsson S, Louis E, Wiman AC, Vermeire S, Rutgeerts P, Belaiche J, et al: An insertion-deletion polymorphism in the interferon regulatory Factor 5 (IRF5) gene confers risk of inflammatory bowel diseases. Hum Mol Genet 2007, 16:3008-3016.

18. Nordmark G: Eloranta ML. Ronnblom L: Primary Sjogren's syndrome and the type I interferon system. Curr Pharm Biotechnol; 2012.

19. Barnes BJ, Moore PA, Pitha PM: Virus-specific activation of a novel interferon regulatory factor, IRF-5, results in the induction of distinct interferon alpha genes. J Biol Chem 2001, 276:23382-23390.

20. Barnes BJ, Kellum MJ, Pinder KE, Frisancho JA, Pitha PM: Interferon regulatory factor 5 , a novel mediator of cell cycle arrest and cell death. Cancer Res 2003, 63:6424-6431.

21. Schoenemeyer A, Barnes BJ, Mancl ME, Latz E, Goutagny N, Pitha PM, Fitzgerald KA, Golenbock DT: The interferon regulatory factor, IRF5, is a central mediator of toll-like receptor 7 signaling. J Biol Chem 2005, 280:17005-17012 
22. Graham RR, Kyogoku C, Sigurdsson S, Vlasova IA, Davies LR, Baechler EC, Plenge RM, Koeuth T, Ortmann WA, Hom G, et al: Three functional variants of IFN regulatory factor 5 (IRF5) define risk and protective haplotypes for human lupus. Proc Natl Acad Sci U S A 2007, 104:6758-6763.

23. Sigurdsson S, Goring HH, Kristjansdottir G, Milani L, Nordmark G, Sandling JK, Eloranta ML, Feng D, Sangster-Guity N, Gunnarsson I, et al: Comprehensive evaluation of the genetic variants of interferon regulatory factor 5 (IRF5) reveals a novel 5 bp length polymorphism as strong risk factor for systemic lupus erythematosus. Hum Mol Genet 2008, 17:872-881.

24. Dudley ME, Yang JC, Sherry R, Hughes MS, Royal R, Kammula U, Robbins PF, Huang J, Citrin DE, Leitman SF, et al: Adoptive cell therapy for patients with metastatic melanoma: evaluation of intensive myeloablative chemoradiation preparative regimens. J Clin Oncol 2008, 26:5233-5239.

25. Dudley ME, Gross CA, Langhan MM, Garcia MR, Sherry RM, Yang JC, Phan GQ, Kammula US, Hughes MS, Citrin DE, et al: CD8+ enriched "young" tumor infiltrating lymphocytes can mediate regression of metastatic melanoma. Clin Cancer Res 2010, 16:6122-6131.

26. Dudley ME, Wunderlich JR, Shelton TE, Even J, Rosenberg SA: Generation of tumor-infiltrating lymphocyte cultures for use in adoptive transfer therapy for melanoma patients. J Immunother 2003, 26:332-342.

27. MacQueen J: Some methods for classification and analysis of multivariate observations. In proceedings of the Fifth Berkeley Symposium on Mathematical Statistics and Probability. Edited by LeCam LM, Neyman J. Berkeley, CA, USA: University of California Press; 1967:281-297.

28. Spivey TL, De Giorgi V, Zhao Y, Bedognetti D, Pos Z, Liu Q, Tomei S, Ascierto ML, Uccellini L, Chouchane L, et al: The stable traits of melanoma genetics: an alternative approach to target discovery. BMC Genomics 2012, 13:156.

29. Wang E, Uccellini L, Marincola FM: A genetic inference on cancer immune responsiveness. Oncoimmunology 2012, 1(4):520-525.

30. Niewold TB, Kelly JA, Kariuki SN, Franek BS, Kumar AA, Kaufman KM, Thomas K, Walker D, Kamp S, Frost JM, et al: IRF5 haplotypes demonstrate diverse serological associations which predict serum interferon alpha activity and explain the majority of the genetic association with systemic lupus erythematosus. Ann Rheum Dis 2012, 71:463-468.

31. Mendez R, Rodriguez T, Del CA, Monge E, Maleno I, Aptsiauri N, Jimenez P, Pedrinaci S, Pawelec G, Ruiz-Cabello F, et al: Characterization of HLA class I altered phenotypes in a panel of human melanoma cell lines. Cancer Immunol Immunother 2008, 57:719-729.

32. Marincola FM, Shamamian P, Alexander RB, Gnarra JR, Turetskaya RL, Nedospasov SA, Simonis TB, Taubenberger JK, Yannelli J, Mixon A, et al: Loss of HLA haplotype and B locus down-regulation in melanoma cell lines. J Immunol 1994, 153:1225-1237.

33. Marincola FM: Mechanisms of immune escape and immune tolerance. In Principles and practice of the biologic therapy of cancer. Third editionth edition. Edited by Rosenberg SA. Philadelphia: Lippincott Williams \& Wilkins; 2000:601-617.

doi:10.1186/1479-5876-10-170

Cite this article as: Uccellini et al: IRF5 gene polymorphisms in melanoma. Journal of Translational Medicine 2012 10:170.

\section{Submit your next manuscript to BioMed Central and take full advantage of:}

- Convenient online submission

- Thorough peer review

- No space constraints or color figure charges

- Immediate publication on acceptance

- Inclusion in PubMed, CAS, Scopus and Google Scholar

- Research which is freely available for redistribution 